\title{
Paraplegia
}

\section{A Comparative Trial of Two Walking Systems for Paralysed People}

M. W. Whittle, MB, PhD, ${ }^{1}$ G. M. Cochrane, FRCP, ${ }^{2}$ A. P.Chase, DipOTC, ${ }^{3}$ A. V. Copping, MCSP, ${ }^{2}$ R. J. Jefferson, $\mathrm{PhD}^{1}{ }^{1}$ D. J. Staples, BSc, ${ }^{2}$ P. T. Fenn, BSc ${ }^{4}$ D. C. Thomas, BSc ${ }^{1}$ ${ }^{I}$ Oxford Orthopaedic Engineering Centre, University of Oxford, ${ }^{2}$ Mary Marlborough Lodge, Nuffield Orthopaedic Centre, ${ }^{3}$ Department of Orthotics, Nuffield Orthopaedic Centre, ${ }^{4}$ Centre for Socio-Legal Studies, University of Oxford, Oxford, UK.

\section{Summary}

A trial has been performed to compare two designs of reciprocal walking orthosis for paralysed people - the hip guidance orthosis (HGO) from Oswestry, England, and the reciprocating gait orthosis (RGO) from New Orleans, USA.

Eighteen male and 4 female paraplegic subjects used each orthosis for 4 months, in a crossover study. All aspects of the provision and use of the devices were monitored, and a variety of assessments were made.

Fifteen subjects were able to use both orthoses, 5 were unable to use either and 2 succeeded with the HGO but not the RGO. At the end of the trial 12 subjects chose to keep the RGO, 4 the HGO, and 6 kept neither. Those choosing the RGO liked its appearance; those choosing the HGO liked the speed of donning and doffing. The RGO was about 50\% more expensive to supply than the HGO.

Key words: Paraplegia; Orthotic devices; Gait.

Two designs of reciprocal walking orthosis for use by the paralysed have now emerged as practical systems. The hip guidance orthosis or HGO (Fig. 1), also called the 'ParaWalker', was developed at the Orthotic Research and Locomotion Assessment Unit, Oswestry, England (Rose, 1979). The reciprocating gait orthosis or RGO (Fig. 2), also called the LSU brace, was developed initially at the Ontario Crippled Children's Centre, Toronto, Canada, and later at Louisiana State University, New Orleans, USA (Douglas et al., 1983).

The general principles of the two orthoses are the same. The body is braced from the mid-trunk to the feet, with the knees and ankles immobilised. The hips are allowed to flex and extend, but are prevented from moving into adduction when the leg is lifted off the ground. 


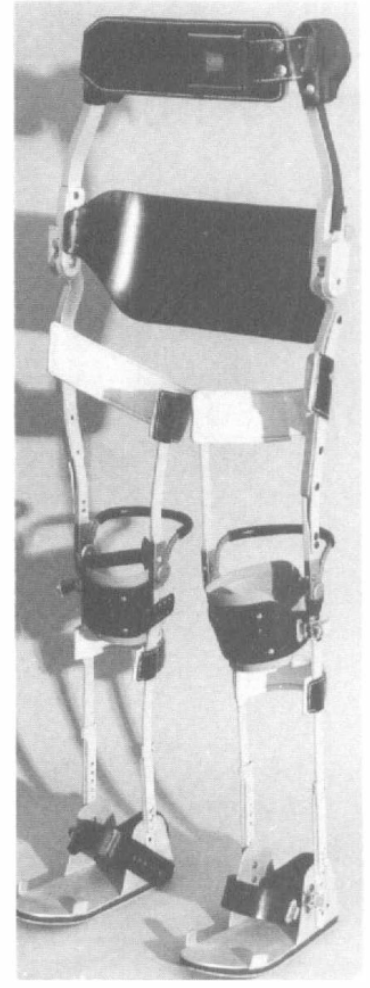

Figure 1 The hip guidance orthosis (HGO)

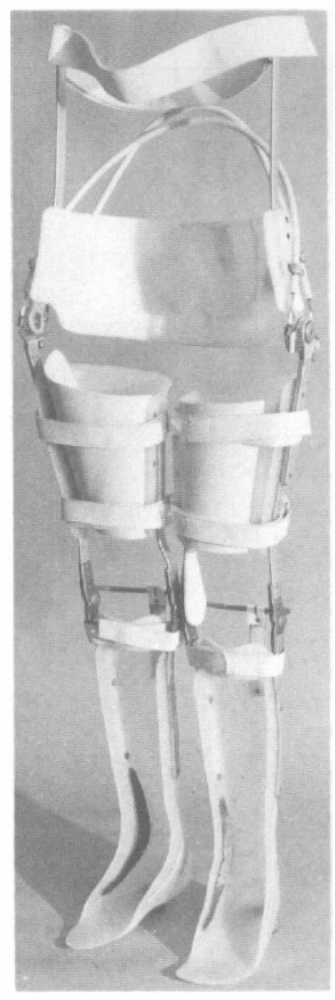

Figure 2 The reciprocating gait orthosis (RGO)

The two orthoses differ in a number of respects. The HGO is less flexible than the RGO, with better control of hip adduction, but it is also heavier. The hip joints on the HGO are free, between flexion and extension stops; on the RGO cables link the two sides, so that extension on one side causes flexion on the other. On the HGO, the subject's shoes fit onto metal plates with rocker soles; the foot section on the RGO is plastic, and fits inside the shoes. The HGO is usually worn outside the clothes; the RGO is designed to be worn under the clothes.

The orthoses must be used with a walking aid. In the case of the RGO this is usually a rollator (a walking frame with wheels at the front). The HGO may also be used with a rollator, but it was designed to be used with crutches.

A comparison of the two orthoses was carried out in Oxford between September 1986 and April 1988 (Whittle and Cochrane, 1989). No member of the reserrch team had been involved in the development of either orthosis.

\section{Methods}

Before commencing the trial, both the orthotist and the physiotherapist received full training in all the relevant aspects of both systems.

A crossover design was used in which 22 adult subjects with traumatic paraplegia (4 female and 18 male) were given the opportunity to use both orthoses. It was 
originally intended to have equal numbers of males and females, but it was impossible to recruit sufficient female subjects.

The subjects were grouped as far as possible into pairs, matched for age and level of spinal injury. After the subject had performed upper limb and trunk exercise for 4 weeks, the first orthosis was fitted, and training was given until the subject could put on and take off the orthosis, to stand up and sit down safely, and to walk at least $30 \mathrm{~m}$. The subject wore the orthosis at home for 4 months, then the pattern was repeated from the beginning for the other orthosis. One member of each pair used the HGO first and the other the RGO first. The guidelines of the originators of the orthoses were followed in that the subjects were encouraged to use crutches with the HGO, and a rollator with the RGO, although they were permitted to use the alternative walking aid if they wished.

Careful records were kept of all aspects of the manufacture and fitting of the orthoses, training in their use, and the opinions of the subjects. In addition, a number of formal assessments were made at appropriate intervals.

\section{Results}

Most subjects were able to use both orthoses, and were enthusiastic about them, although the training was more arduous than they expected. The table shows, for each subject, brief clinical details, whether they were successful in using the two orthoses, whether they used crutches or a rollator and which orthosis they opted to keep.

Table List of subjects giving clinical details and trial outcome

\begin{tabular}{|c|c|c|c|c|c|c|c|}
\hline Sex & Age & $\begin{array}{c}\text { Spinal } \\
\text { level }\end{array}$ & $\begin{array}{l}\text { Walking aid } \\
\text { with HGO }\end{array}$ & $\begin{array}{l}\text { Walking aid } \\
\text { with RGO }\end{array}$ & $\begin{array}{c}\text { Success } \\
\text { with } \mathrm{HGO}\end{array}$ & $\begin{array}{c}\text { Success } \\
\text { with RGO }\end{array}$ & $\begin{array}{c}\text { Final } \\
\text { choice }\end{array}$ \\
\hline M & 33 & T3 & Crutches & Rollator & No & No & None \\
\hline $\mathbf{M}$ & 39 & T3 & Rollator & Rollator & Yes & No & HGO \\
\hline M & 31 & $\mathrm{~T} 4$ & Crutches & Rollator & Yes & No & None \\
\hline M & 26 & $\mathrm{~T} 4$ & Rollator & Rollator & Yes & Yes & RGO \\
\hline M & 35 & T4 & $\star$ & Rollator & $\star$ & No & None \\
\hline F & 43 & $\mathrm{~T} 4$ & Rollator & Rollator & Yes & Yes & RGO \\
\hline F & 31 & T5 & $\star$ & Rollator & $\star$ & No & None \\
\hline M & 32 & T5 & Crutches & Rollator & Yes & Yes & RGO \\
\hline M & 26 & T5 & Crutches & Rollator & Yes & Yes & HGO \\
\hline$M$ & 39 & T6 & Rollator & Rollator & Yes & Yes & RGO \\
\hline $\mathbf{M}$ & 29 & T6 & Crutches & Rollator & Yes & Yes & RGO \\
\hline M & 29 & T6 & Crutches & Rollator & Yes & Yes & HGO \\
\hline$M$ & 36 & T6 & Rollator & Rollator & Yes & Yes & RGO \\
\hline M & 35 & T7 & Crutches & Rollator & Yes & Yes & RGO \\
\hline M & 32 & $\mathrm{~T} 7$ & Crutches & Rollator & Yes & Yes & RGO \\
\hline M & 44 & T11 & Crutches & Rollator & Yes & Yes & RGO \\
\hline M & 31 & T11 & Crutches & Rollator & Yes & Yes & HGO \\
\hline F & 32 & T11 & $\star$ & $\star$ & $\star$ & $\star$ & None \\
\hline F & 41 & T12 & Crutches & $\star$ & No & $\star$ & None \\
\hline M & 35 & T12 & Crutches & Rollator & Yes & Yes & RGO \\
\hline M & 21 & $\mathrm{~T} 12$ & Crutches & Crutches & Yes & Yes & RGO \\
\hline M & 39 & $\mathrm{~T} 12$ & Crutches & Rollator & Yes & Yes & RGO \\
\hline Totals: & & & $\begin{array}{lr}\text { Crutches } & 14 \\
\text { Rollator } & 5\end{array}$ & $\begin{array}{lr}\text { Crutches } & 1 \\
\text { Rollator } & 19\end{array}$ & $\begin{array}{lr}\text { Yes } & 17 \\
\text { No } & 3\end{array}$ & $\begin{array}{lr}\text { Yes } & 15 \\
\text { No } & 5\end{array}$ & $\begin{array}{lr}\text { RGO } & 12 \\
\text { HGO } & 4 \\
\text { None } & 6\end{array}$ \\
\hline
\end{tabular}

$\star=$ subject left trial without using this orthosis 


\section{Measurement, fabrication and fitting}

Both orthoses required considerable skill and experience in fitting. The orthotist and technicians all needed extensive training.

Frequent adjustments were needed initially for both orthoses; this was relatively easy in the present study as the orthotist was on site. Vigilance was needed to avoid pressure sores, particularly with the RGO.

No major failures occurred with the HGO, but two subjects damaged the RGO by overstressing it. With both orthoses, about one third of the subjects needed minor repairs, replacements or adjustments during 4 months of use.

\section{Subject training}

For both orthoses, the subjects benefited from upper limb exercises and familiarisation with the upright position before the orthosis was fitted. Success with either orthosis depended to some extent on physical fitness. The use of an orthosis improved both fitness and upper limb strength.

Initial standing was easier in the RGO, because of the inter-linkage of the hip joints. Learning to use a rollator with the RGO was very much easier than learning to use crutches with the HGO. Standing up from sitting was also much easier with a rollator than with crutches. Training in the use of either orthosis generally took about 3 hours per day for 4 to 5 days.

\section{Ergonomic assessment}

After 4 months, almost all the subjects could complete a series of 10 ergonomic tests using the RGO; a few failed or needed help when using the HGO. The greatest difficulties were experienced in climbing up and down a curb, and in walking up and down a slope.

The HGO was much quicker to put on or to take off. The RGO was quicker on most of the other tests, but this was statistically significant only for standing up and climbing up a curb.

When sitting in a wheelchair, wearing an orthosis did not cause any serious problems. It was difficult to use a car when wearing one of these orthoses, as either driver or passenger, although it was a little easier with the RGO.

The main reasons given for the final choice were:

HGO - ease of putting on and taking off.

RGO - cosmesis and ease of standing with hands free;

Neither - fear of developing pressure sores, and difficulty in using either orthosis.

\section{Biomechanical assessment}

There were no statistically significant differences between the orthoses in the general gait parameters (cadence, stride length and velocity) after 4 months use. The average walking velocity with both orthoses was about $0.24 \mathrm{~m} / \mathrm{s}$, which is about one fifth of normal.

A different pattern of movement was observed between the two orthoses, due partly to the differences in walking aids, and partly to the fact that the HGO is 
more resistant to adduction of the hip. The effort involved in walking, estimated by changes in pulse rate and oxygen consumption, was similar for the two orthoses.

\section{Psychological assessment}

The final choice did not appear to be influenced by intelligence or by any previous knowledge of one or other orthosis. The RGO was preferred by those who tended to be anxious, and also by those who did not regard themselves as particularly persistent in the face of difficulty.

Comfort was stated to be the most important feature of an orthosis for most people, and appearance was regarded as being of lesser importance. However, there was little difference in comfort between the two orthoses, and the better cosmesis of the RGO then became a reason for preferring it.

\section{Economic assessment}

The only statistically significant difference in cost between the two orthoses was in the fabrication. This averaged $£ 1116$ for the HGO and $£ 1772$ for the RGO. Three quarters of the difference was due to labour costs, the remainder due to the cost of materials.

Other costs, such as training and out-of-pocket expenses, were similar between the orthoses. The combined cost of training and of 4 months maintenance was about $£ 330$ for each device. The subjects and their carers had an average of 8 days off work and out-of-pocket expenses of $£ 160$ to $£ 200$.

A full description of all aspects of the trial was published as a report in the 'Health Equipment Information' series (Whittle and Cochrane, 1989).

\section{Discussion}

Most paralysed people manage extremely well using a wheelchair. Compared with the walking of normal people, it is both faster and more energy efficient (Whittle, 1988), although it suffers from some disadvantages, such as a lack of eye contact, and difficulties with narrow entrances and steps. Clearly most wheelchair users would much prefer to be able to walk normally. However, the type of walking currently available using these orthoses is not normal, and is expensive in terms of time, money and effort. It is therefore only appropriate for those individuals who have the determination to succeed.

The aim of the trial was not to find a 'winner', but rather to give guidance to prescribers as to which subjects are likely to be unsuitable for either orthosis, and which can be expected to do better in one than in the other.

The fact that more subjects chose the RGO than the HGO at the end of the trial may give a misleading impression on the relative merits of the two devices, since the trial did not compare the two orthoses in isolation, but rather the combination of the orthosis and its walking aid. There can be no doubt that a rollator is easier to use than crutches, and this tended to bias subjects against the HGO, which was designed to be used with crutches if at all possible.

Another perturbing factor, which again might have operated slightly against the $\mathrm{HGO}$, is that the time taken to train the subjects had to be kept to a minimum, 
since they were to be fitted with two orthoses in a single year. It takes longer to achieve proficiency with crutches than with a rollator, so that although no subject was sent home until he or she was walking adequately and safely, the level of confidence may have been less in those using the HGO with crutches. The originators of both orthoses suggest a training period of 3 weeks; the present authors believe that this is both unnecessary and unrealistic, and could mitigate against the use of these devices by those who have difficulty in getting time away from their employment or domestic duties.

\section{Conclusions}

There is a need for a team approach by the physician or surgeon, orthotist, physiotherapist and technician. The assessment must include the physical and psychological characteristics of the person who will use the orthosis, the circumstances at home, at work and in travelling, and the certainty of sustained enthusiasm and encouragement by others. The choice of orthosis will depend on these factors, as well as on physical factors such as spasticity, flexion contractures, ankle oedema and a tendency to develop pressure sores.

The fabrication and fitting of the orthoses and training in their use should ideally be undertaken only where the orthotist, orthotic technicians, workshop facilities and physiotherapist are on the same site. The best results will be obtained if, after training, further assistance is available from a physiotherapist who has experience of the orthosis.

There are no absolute contra-indications to the use of either orthosis, although as a general rule the higher the spinal lesion the more difficulty is likely to be experienced, and the less satisfactory the gait.

The potential user must appreciate the limitations of ambulatory orthoses, especially the physical effort involved in standing up and in walking, the slowness and the short distances which can be travelled. There is a marked contrast with the speed, precision and ease of use of a wheelchair.

Before a decision is reached, the paraplegic person should demonstrate his or her determination to succeed by losing excess weight and by gaining strength in the muscles of the upper trunk, the pectoral girdle and the arms.

\section{References}

Douglas R, LaRson PF, D'Ambrosia R, McCall RE 1983 The LSU reciprocation-gait orthosis. Orthopedics 6:834-838.

RosE GK 1979 The principles and practice of hip guidance articulations. Prosthetics Orthotics International 3:37-43.

WhITTLE MW 1988 Paraplegic Locomotion. Clinical Rehabilitation 2:45-49.

WhitTLE MW, COCHRANE GM 1989 A comparative trial of the hip guidance orthosis and the reciprocating gait orthosis. Health Equipment Information series No. 192, HM Stationery Office, London. 